\title{
O Cancelamento de Bens Tombados como Instrumento de Poder no Estado Novo: interlocuções com as discussões de poder e de agência de Sherry B. Ortner
}

\author{
Cristiane Bade ${ }^{1}$ \\ ${ }^{1}$ Universidade Federal de Pernambuco, Recife, PE, Brasil
}




\section{Resumo}

Este texto apresenta algumas reflexões acerca de um procedimento jurídico usado para o exercício do poder. Os mecanismos de exercício de poder são solidificados em distintos instrumentos, mas aqui será considerado especificamente aquele que permite o cancelamento de bens tombados, o qual foi criado no Estado Novo (1937-1945) e ainda versa a lei que organiza a proteção do patrimônio histórico e artístico brasileiro. Para essa análise, busca-se fazer interlocuções com a discussão de poder e de agência da antropóloga Sherry Ortner.

Palavras-chave: Patrimônio Histórico. Poder. Agência. Memória.

\section{Abstract}

The following text has some reflections on a procedure used for the exercise of power. The mechanisms for the exercise of power are solidified in different instruments, but here is the actor who allows the change of assets that were created in the Estado Novo (1937-1945) and, in addition, a law that organizes a protection of Brazilian historical and artistic heritage. For this analysis, make interlocutions with a power session and an agency of the anthropologist Sherry Ortner.

Keywords: Historical Patrimony. Power. Agency. Memory. 


\section{Introdução}

cancelamento de bens tombados no Brasil é um ato previsto no Decreto-Lei n. 25, de 30 de novembro de 1937, que versa pela organização da proteção do patrimônio histórico e artístico brasileiro. A partir desse decreto, diferentes organizações e corporações da sociedade civil e política têm se apropriado dessa abertura na legislação e cancelado bens objetivando projetos de poder.

A questão do cancelamento de bens patrimoniais no Brasil não tem ganhado a devida atenção nos estudos acadêmicos, em especial, acerca do patrimônio cultural. Com esse texto, busco discutir algumas situações de descaso com o patrimônio histórico a partir do cancelamento de bens, bem como apresentar este ato administrativo como instrumento de poder a serviço de projetos.

Para melhor apreciação dessa questão, optou-se por analisar o período do Estado Novo (1937-1945). Essa escolha justifica-se por ser o período de instituição do Decreto-lei que versa sobre o cancelamento e por apresentar um número expressivo desse ato administrativo.

Neste artigo trata-se sobre a temática do poder relacionado à memória social no período do Estado Novo. Desse modo, procuro articular essa temática ao texto "Poder e projetos: reflexões sobre a agência", de Sherry B. Ortner, uma das antropólogas norte-americanas mais eminentes.

Parte do resultado deste artigo é decorrente de uma pesquisa bibliográfica, levantada a partir de inquietações que tive durante o transcorrer da minha atuação em um programa de extensão ${ }^{1}$ e um projeto de pesquisa ${ }^{2}$, vinculados ao curso de Artes Visuais da Universidade Federal de Roraima. No desenvolvimento desse projeto 
e desse programa, observou-se que parte dos bens tombados no centro histórico da cidade de Boa Vista, Roraima, tinha sido modificada ou demolida, em especial, nas gestões da prefeita Teresa Surita (19931996; 2001-2004; 2004-2008; 2012-2016). Além disso, no período, vários bens estavam sendo cancelados de maneira irregular, ou seja, o município cancelava bens que tinham sido tombados a nível estadual. Esse conjunto de experiências resultou em curiosidade por entender a recorrência que essas práticas de cancelamento haviam sido realizadas no Brasil. Assim, fui percebendo que as leis de preservação seguiam os ditames de períodos extremamente autoritários e opressores, no Brasil.

Diante dessa realidade, fiz levantamentos de autores que já se debruçaram sobre essa questão ao longo dos anos, e encontrei um importante estudo on-line, do pesquisador Celso Lago Paiva, que disponibiliza uma catalogação dos bens de pedra e cal destruídos no Brasil, sejam eles tombados ou com seus efeitos cancelados. A partir desse autor, percebi que os maiores casos de bens cancelados e demolidos no Brasil ocorreram no período do Estado Novo. Diante disso, realizei uma pesquisa mais apurada na legislação para saber quando esse ato legislativo foi criado no Brasil.

Em seguida, pesquisei os casos apontados pelo pesquisador Celso Lago Paiva, no período do Estado Novo, e três casos de cancelamento e posterior demolição de bens patrimoniais me chamaram mais atenção nesse período, pois priorizam o patrimônio construído no cotidiano de uma elite em detrimento de povos historicamente regados ao silenciamento.

Entretanto, destaca-se que o uso das imagens busca mostrar no campo visual a paisagem do período, bem como os prédios demolidos, ou seja, elas não fazem parte do foco dessa análise.

Este artigo, desse modo, está estruturado em três seções. Na primeira parte faço uma discussão em torno das políticas de proteção ao patrimônio cultural no Brasil. Essa discussão é fundamental para a compreensão da disposição e atuação das políticas de proteção do patrimônio; na segunda parte do texto, intitulada "O papel da instituição do tombamento na construção da identidade nacional", será dada uma atenção especial ao período de instituição do Decreto-Lei que permitiu 
o cancelamento do tombamento de bens pertencentes à União, aos Estados e Municípios. A ideia central dessa parte é compreender como a instituição desse ato administrativo contribuiu para o esquecimento da memória de alguns grupos sociais e criou uma nova identidade no Brasil; para encerrar a discussão, analiso a ação administrativa do cancelamento como instrumento de dominação da memória social fazendo interlocuções com o trabalho de Ortner. Nessa parte apresento como esse ato é um meio de poder e dominação de alguns grupos sociais, por meio da análise de três casos de cancelamento a nível federal, que ocorreram durante o Estado Novo.

Para tratar desses eventos, foi preciso contextualizar os valores correspondentes ao projeto de construção de identidade nacional, pois só assim esses casos teriam sentido ao leitor. Desse modo, é pertinente ressaltar que "[...] os eventos não podem ser entendidos, portanto, separados de seus valores correspondentes: é a significância que transforma um simples acontecimento em uma conjuntura fatal" (SAHLINS, 1990, p. 191).

\section{Políticas de Proteção ao Patrimônio no Brasil}

No início dos anos 1920, a preocupação com o patrimônio histórico nacional sofreu uma guinada, expressa na pressão exercida por intelectuais para um olhar mais atento para a conservação dos bens patrimoniais. Assim, começaram a surgir os primeiros indícios que assinalam para uma maior preocupação com o patrimônio histórico brasileiro:

A preocupação com a preservação do patrimônio histórico nacional, principalmente dos bens imóveis fora do âmbito dos museus, começa a ter um significado mais relevante a partir da década de 1920, visto que a falta de preservação destes bens estava comprometendo sua conservação, chamando assim a atenção de intelectuais, que denunciavam o descaso com as cidades históricas e a dilapidação do que seria um "tesouro" Nacional. (TOMAZ, 2010, p. 7)

Nesse período foram elaborados os primeiros projetos de lei que fazem menção a proteção do patrimônio. Um desses projetos foi do 
deputado Augusto de Lima (1924), que tinha como ponto central a proibição da saída das obras de arte brasileiras, pois, no período, existia muita evasão destas para o exterior (PINHEIRO, 2006).

Porém, as iniciativas de preservação do patrimônio só começaram a ter seus primeiros efeitos significativos na década de 1930:

O primeiro deles data de 1933, quando a cidade de Ouro Preto foi declarada monumento nacional, em reconhecimento a seu rico passado histórico - palco da Inconfidência Mineira - e a seu opulento patrimônio edificado, a maior parte do qual era àquela altura atribuído ao gênio máximo da arte colonial, o mítico Aleijadinho. (PINHEIRO, 2006, p. 7)

Para ampliação da proteção e reconhecimento dos bens patrimoniais no Brasil, foi criada, em 13 de janeiro de 1937 (Lei n. 378), uma autarquia federal, chamada na época de Serviço de Patrimônio Histórico e Artístico Nacional (SPHAN)³, que versava sobre a nova organização do Ministério da Educação e Saúde Pública.

Nesse âmbito, foram criadas políticas públicas para a proteção dos bens patrimoniais no Brasil. A instituição do tombamento, prevista no Decreto-Lei n. 25, de 30 de novembro de 1937, foi uma dessas medidas tomadas para a preservação dos bens. Cabe, também, destacar que o momento político do país - governo ditatorial de Getúlio Vargas ${ }^{4}$ - tem profunda relação com essas políticas, pois o Brasil buscava a construção de uma identidade nacional. Nesse caso, compete salientar que na época essas iniciativas de proteção deram enfoque e priorizaram bens materiais ligados à Igreja, corporações e a famílias com grande poder econômico e político.

Na instituição do Decreto-Lei n. 25, de 30 de novembro de 1937, que organiza a proteção do patrimônio histórico e artístico nacional, já estava previsto, no artigo 19, parágrafos $1^{\circ}$ e $2^{\circ}$, o cancelamento de bens patrimoniais:

Art. 19. O proprietário de coisa tombada, que não dispuzer de recursos para proceder às obras de conservação e reparação que a mesma requerer, levará ao conhecimento do Serviço do Patrimônio Histórico e Artístico Nacional a necessidade das mencionadas obras, sob pena de multa 
correspondente ao dobro da importância em que fôr avaliado o dano sofrido pela mesma coisa.

$\S 1^{\circ}$ Recebida a comunicação, e consideradas necessárias as obras, o diretor do Serviço do Patrimônio Histórico e Artístico Nacional mandará executá-las, a expensas da União, devendo as mesmas ser iniciadas dentro do prazo de seis mezes, ou providenciará para que seja feita a desapropriação da coisa.

$\S 2^{\circ}$ À falta de qualquer das providências previstas no parágrafo anterior, poderá o proprietário requerer que seja cancelado o tombamento da coisa. (BRASIL, 1937, art. 19)

Contudo, alguns anos depois, o presidente Getúlio Vargas alterou o texto que versava sobre o cancelamento de bens tombados, instituindo o Decreto-Lei n. 3.866 de 1941:

O Presidente da República, atendendo a motivos de interesse público, poderá determinar, de ofício ou em grau de recurso, interposto pôr qualquer legítimo interessado, seja cancelado o tombamento de bens pertencentes à União, aos Estados, aos municípios ou a pessoas naturais ou jurídicas de direito privado, feito no Serviço do Patrimônio Histórico e Artístico Nacional. (BRASIL, 1941, artigo único)

Com o decreto, o cancelamento passa somente por uma instância, ou seja, a crivo do presidente, desde que seja de "interesse público". Pelo exposto, percebe-se que a decisão de cancelamento não passa por uma discussão da sociedade onde o bem está inserido quando pertencente aos estados ou municípios, ou uma discussão mais ampla quando o bem for tombado pela união.

Nas décadas póstumas, raras modificações foram inseridas no que versa a legislação sobre o cancelamento de bens. A partir da Lei n. 6.292, de 15 de dezembro de 1975, o cancelamento de tombamento retorna aos procedimentos previstos no Decreto-Lei n. 25/37.

A partir do ano de 2000, foi instituído o Decreto-Lei n. 3.551, que regulamenta o registro de bens imateriais. Assim, passam a ser valorizados saberes, modos de fazer, celebrações, ofícios. Cabe lembrar que este último instrumento apenas valoriza o patrimônio, não atua com medidas de tutela (FUNARI; PELEGRINI, 2009). 
Pelo exposto, é possível observar que as leis omitem um papel significativo sobre os processos de preservação patrimonial, o qual se consolida pela participação popular na seleção dos bens que serão preservados.

\section{O Papel da Instituição do Tombamento na Construção da Identidade Nacional}

O tombamento é um meio de salvaguarda e reconhecimento de bens culturais. Essa ação administrativa é um dos meios legais para evitar a destruição do patrimônio material. Contudo, no Brasil a instituição legal desse ato tem muitas brechas e permite com certa facilidade o cancelamento. Essa abertura na constituição tem possibilitado que os representantes das diferentes esferas do poder público façam o cancelamento para beneficiar economicamente sua família ou grupos ligados à sua gestão. É importante frisar que o tombamento não é o único instrumento de preservação no Brasil de bens patrimoniais, como já apontamos anteriormente, também existe a lei que versa sobre o registro de bens imateriais.

O Decreto-Lei n. 25, de 30 de novembro de 1937, que trata da instituição do tombamento, contribuiu para a consolidação de um projeto de construção da cultura brasileira, que buscou unificar a sociedade daquele período por meio da criação de uma identidade nacional. Nesse sentido, o contexto político e econômico brasileiro da década de 1930

[...] figurava um direcionamento político cuja ideologia calcava-se na afirmação dos valores nacionais e na reformulação da sociedade através da construção da identidade nacional, e cujas bases deveriam apoiar-se na segurança nacional e na educação. [...] Era o Estado promovendo o desenvolvimento da nação, e a palavrachave era modernização. (GONÇALVES, 2007, p. 29)

A construção da identidade nacional começou a ser discutida no Brasil no início do século XX. Destarte, as autarquias governamentais selecionaram tradições e costumes para instituir uma identidade nacional. Igualmente, também é importante frisar que "[...] as 
identidades nacionais não são coisas com as quais nós nascemos, mas são formadas e transformadas no interior da representação" (HALL, 2003, p. 48).

Assim, a fim de nos caracterizar como nação brasileira, a autarquia do Serviço do Patrimônio Histórico e Artístico Nacional (SPHAN) selecionou a partir da década de 1930 bens materiais e os reconheceu como patrimônio histórico e artístico nacional, adotando medidas de preservação das memórias e da cultura da elite brasileira, deixando de lado nesse momento outros sujeitos que fazem parte da formação da identidade nacional, como destacou Pelegrini:

Nessa linha interpretativa, faz-se necessário admitir que o reconhecimento do patrimônio cultural brasileiro oficial ficou circunscrito ao tombamento das obras de arte, de monumentos e de conjuntos arquitetônicos considerados de alto valor histórico ou de antiguidade, na sua maioria, de propriedade do Estado e da Igreja Católica. (PELEGRINI, 2009, p. 80)

Nesse sentido, é importante caracterizar que a construção de uma identidade nacional não envolve uma simples união e assimilação simbólica, “[...] ela é também uma estrutura de poder cultural [...]", retomando aqui os termos de Hall (2003, p. 59).

Dessa forma, o projeto reproduzido e disseminado pelo Estado no período do Estado Novo não visava apenas à criação de instrumentos de poder para a invenção de uma identidade nacional, mas também o poder e a dominação da memória social, objeto da discussão daqui em diante.

\section{Jogos Sérios: o cancelamento como instrumento de poder e dominação ${ }^{5}$ no Estado Novo}

Antes de iniciar a discussão de poder e dominação da memória social no Estado Novo, gostaria de introduzir a discussão que Ortner faz sobre os conceitos norteadores da análise dessa seção: agência e jogos sérios. Ortner (2007), no texto "Poder e projetos: reflexões sobre a agência", enfatiza a discussão de agência e poder buscando discutir um conceito mais amplo, o qual chamou de "jogos sérios". Esse conceito, segundo 
a autora, “[...] permite-nos dar nitidez às formas mais complexas de relações sociais, especialmente relações de poder, e as dimensões mais complexas da subjetividade dos atores sociais (ORTNER, 2007, p. 46). Nesse sentido, este último conceito nos permite compreender melhor as extensões que abrangem as relações de poder e as subjetividades dos atores envolvidos.

Exemplificando essa questão, mais adiante, quando apresento o caso analisado de cancelamento e posterior demolição da Igreja de São Pedro dos Clérigos, localizada no Rio de Janeiro, veremos bem essa situação, quando Getúlio Vargas, que era detentor do poder na decisão total no Estado Novo, usava o poder de decisão nas instâncias de patrimônio, em prol de projetos de uma elite historicamente priorizada.

Além disso, utilizo o conceito de agência de Ortner para discutir a questão do poder, pois o cancelamento atua como instrumento de organização e seleção da memória social. A autora destaca ainda que a categoria agência tem dois campos de significados:

Em um campo de significado, "agência" tem a ver com intencionalidade e com o fato de perseguir projetos (culturalmente definidos). No outro campo de significado, agência tem a ver com poder, com o fato de agir no contexto de relações de desigualdade, de assimetria e de forças sociais. Na realidade, "agência" nunca é meramente um ou outro. Suas duas "faces" - como (perseguir) "projetos" ou como (o fato de exercer ou de ser contra) o "poder" ou se misturam/transfundem um no outro, ou mantêm sua distinção, mas se entrelaçam em uma relação de tipo Moebius. Além disso, o poder, em si, é uma faca de dois gumes, operando de cima para baixo como dominação, e de baixo para cima como resistência. (ORTNER, 2007, p. 58)

Desse modo, para a autora todos os indivíduos têm agência, “[...] mas a ideia de atores como sempre envolvidos com outros na operação dos jogos sérios visa a tornar praticamente impossível imaginar-se que o agente é livre ou que é um indivíduo que age sem restrições. (ORTNER, 2007, p. 47)

É preciso lembrar que agência não é uma coisa em si, mas faz parte de um processo de estruturação, como muito bem salientou Ortner. 
Voltando à questão do cancelamento, é preciso enfatizar outras discussões antes de analisarmos os casos propriamente. Assim, é preciso perguntar por que precisamos discutir sobre o cancelamento do tombamento? A anulação da proteção colabora com a descaracterização do bem ou sua demolição. A destruição resulta no apagamento do passado. A memória não é espontânea, ela necessita de objetos e lugares para ser exteriorizada (NORA, 1993). Desse modo, o cancelamento favorece o esquecimento.

O que a discussão antropológica pode oferecer, nesse sentido, é a ideia de que as relações de poder favorecem a criação de instrumentos de seleção da memória, colocando em risco outras categorias culturais, como ressaltou Marshall Sahlins em Ilhas da história. Os homens em seus projetos práticos e em seus arranjos sociais, informados por significados de coisas e de pessoas, submetem as categorias culturais a riscos empíricos (SAHLINS, 1990, p. 9).

Assim, a ação administrativa do cancelamento é um instrumento de poder e dominação da memória social, pois ela favorece o apagamento da memória de alguns grupos sociais. Desse modo, para a análise mais sistematizada dessa questão, selecionei três casos de cancelamento no Brasil no período do Estado Novo.

Tendo como pressuposto a passagem anterior, que compreende o cancelamento como instrumento de poder, seria falacioso omitir que existem diferentes modos de poder, como nos lembra o antropólogo Éric Wolf.

[...] falamos freqüentemente de poder como se todos os fenômenos que o envolvem fossem de alguma forma redutíveis a um centro comum, a alguma essência interna. Isso traz à mente imagens monstruosas de poder, o Leviatã de Hobbes ou o Minotauro de Bertrand de Jouvenel, mas nos afasta de especificar os diferentes tipos de poder implicados em tipos diversos de relações. (WOLF, 2003, p. 325)

Nesse sentido, o primeiro caso que apresentarei é o cancelamento do tombamento da Igreja de Nossa Senhora do Rosário (Figura 1). Essa instituição estava localizada no município de Porto Alegre, estado do 
Rio Grande do Sul e foi construída entre 1817-1827, aproximadamente. A história da Igreja de Nossa Senhora do Rosário, de Porto Alegre, liga-se aos negros escravos e libertos que compunham a irmanda do Rosário. O tombamento desse prédio foi em 1938 a nível federal, sendo realizado pela SPHAN (TANCCINI, 2008).

Figura 1: Igreja Nossa Senhora do Rosário

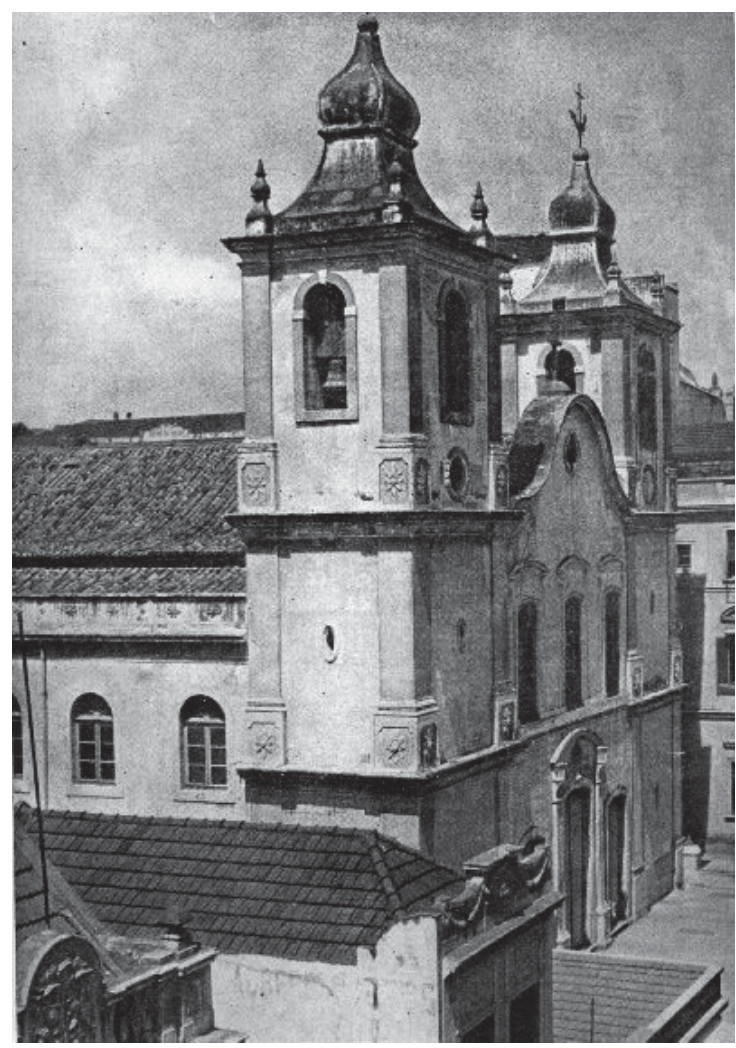

Fonte: Arquivo de Ivan Dorneles Rodrigues (2013)

O processo de tombamento desse prédio envolveu divergentes interesses. De um lado, os clérigos da arquidiocese com o objetivo de construir uma nova Igreja ampla e imponente, buscando construir uma nova identidade para esta, diferente daquela que ligava aos negros e escravos libertos. Opuseram-se, portanto, ao tombamento, sob a alegação de que a Igreja era pequena e em processo de deteriorização (TANCCINI, 2008). 
Todavia, quando se trata das relações sociais, mais precisamente usando o conceito "jogos sérios", de Ortner, é preciso ressaltar que existe a possibilidade de resistência:

É preciso assinalar que os diferenciais de poder dentro do que se supõe serem grupos ou entidades sociais (no caso, as famílias) com metas compartilhadas também são, em última instância, a base da instabilidade de todos os jogos. Aqui, temos de introduzir a terceira peça da "estrutura elementar": a onipresente possibilidade de "resistência". A possibilidade de resistência é uma das partes mais nebulosas e, obviamente, nem sempre percebida da estrutura, mas é, de todo modo, parte da estrutura. Isto é verdade porque os atores subordinados nunca são completamente destituídos de agência, exceto talvez nos contos de fadas. (ORTNER, 2007, p. 70-71)

No caso analisado, existiu um grupo formado pelo SPHAN e intelectuais, que defendia a preservação do bem como patrimônio histórico e artístico nacional, devido ao prédio ser edificado no estilo barroco, como pode ser observado na Figura 1. No entanto, os esforcos desse grupo não impediu que esse bem foi demolido.

Em 1941, esse bem foi cancelado e demolido na década de 1950 para a construção de uma nova igreja. A destruição da memória coletiva de um grupo é uma das formas mais eficazes de dominação e desagregação social (FONSECA, 2001, p. 88).

A revogação do tombamento levou ao apagamento da memória social ligada à história de negros e escravos libertos, assim percebo que a dominação social é mediada por estruturas simbólicas que operam em todas as dimensões na busca pela legimitação de poder cultural dos grupos que detêm o poder. Desse modo, considero o cancelamento como um instrumento de dominação da memória social de uma elite historicamente priorizada pelas políticas públicas de patrimonialização do Estado Novo, em detrimento de povos historicamente relegados aos esquecimentos/silenciamentos de suas memórias.

Nesse caso também se apresenta aquilo que Ortner (1997, p. 12, grifo meu) conceituou de agência, na medida que os atores, clérigos da arquidiocese, "[...] jogaram com habilidades, sabedoria, conhecimento 
e inteligência $[\ldots]$ ", para que essa memória de grupos historicamente relegados ao esquecimento fosse silenciada.

O segundo caso que escolhi é o processo de cancelamento do tombamento do centro histórico da cidade de São João Marcos (Figura 2), localizado no estado do Rio de Janeiro. A abertura do processo de tombamento do centro histórico da cidade foi em 1938. No processo estavam descritos um conjunto de edificações residenciais e uma edificação de uso religioso, urbanas, cemitério, calçada de pedras e sítio arqueológico (RADUN; COELHO, 2015).

Figura 2: São João Marcos

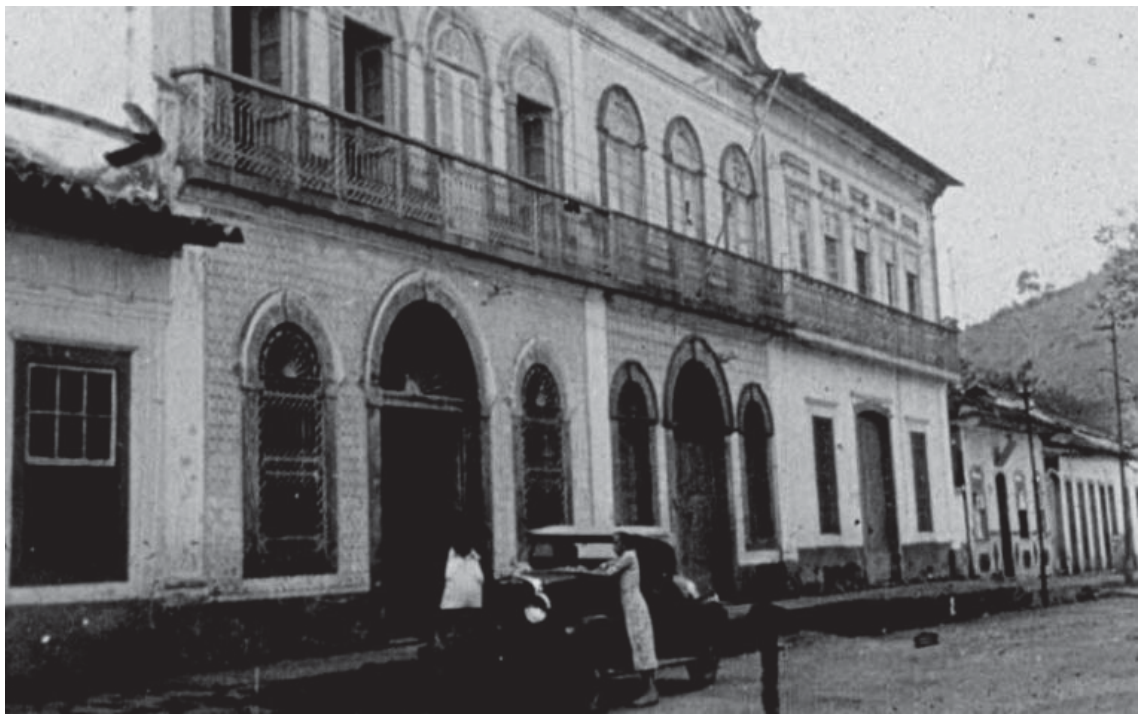

Fonte: Arquivo do parque ecológico e ambiental de São João Marcos

No processo de tombamento surgiram contestações por parte da empresa Cia Carris Luz e Força do Rio de Janeiro. A empresa alegou que "[...] é necessário inundar a cidade para se cumprir o compromisso de fornecer eletricidade ao Rio de Janeiro" (RADUN; COELHO, 2015, p. 5). Mesmo com essas polêmicas, em 1939, o SPHAN determinou o tombamento de São João Marcos.

Um ano após o tombamento, Getúlio Vargas institui o Decreto-Lei n. 2.269, de 3 de junho de 1940, que: 
Concede à Companhia de Carrís, Luz e Força do Rio de Janeiro, Limitada, direito de desapropriação de terras no Município do Rio Claro, Estado do Rio de Janeiro, suspendendo, para esse fim, os efeitos do Decreto-Lei $n^{\circ}$ 25 de 30 de novembro de 1937.

Em 1940 a cidade começou a ser demolida. Mesmo depois da ampliação da barragem de Ribeirão das Lajes, o centro da cidade não ficou totalmente debaixo d'água porque a represa nunca foi usada em sua capacidade máxima (MOUTINHO, 2012). O último prédio a ser demolido na cidade foi a Igreja Matriz (Figura 3):

Figura 3: Fundos da antiga Igreja Matriz

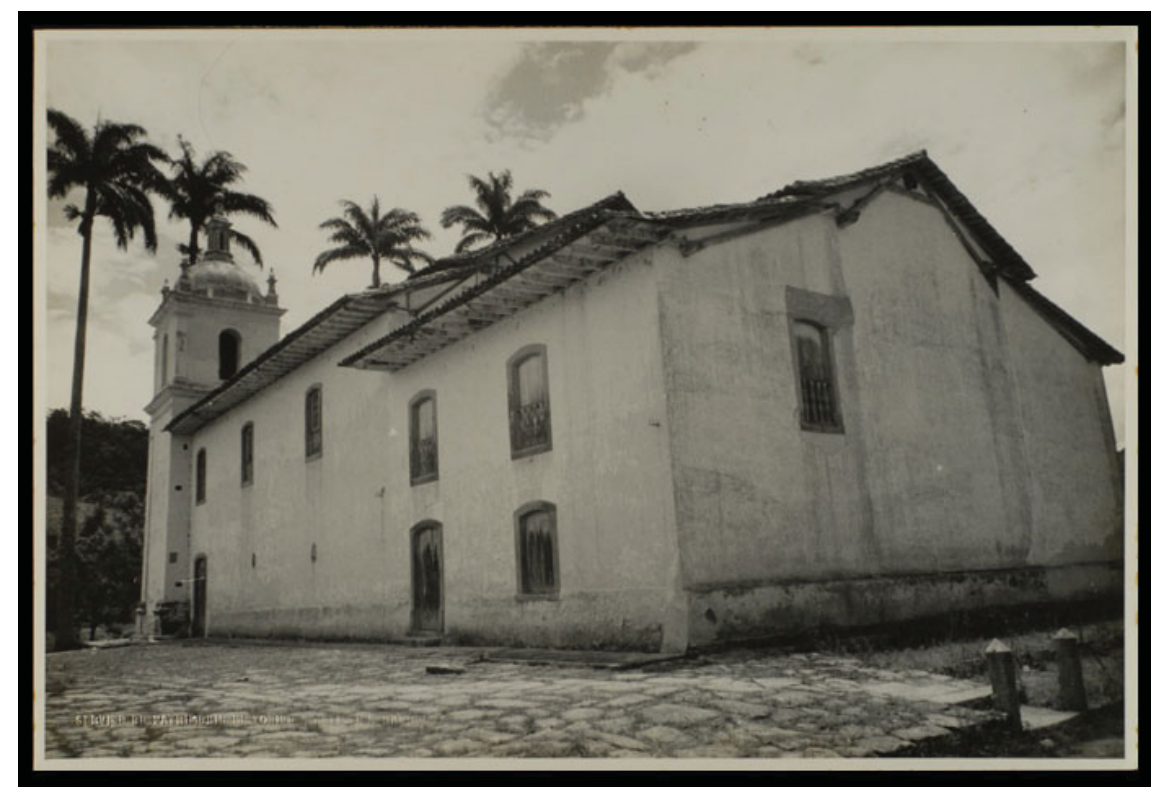

Fonte: Arquivos do Instituto Light

Atualmente, grande parte da cidade está abandonada, apenas funciona na região um Parque Arqueológico e Ambiental de São João Marcos. Na cidade, remanecentes das antigas construções ainda podem ser vistas, como pode ser observado na figura a seguir: 
Figura 4: Restos da Antiga Igreja Matriz

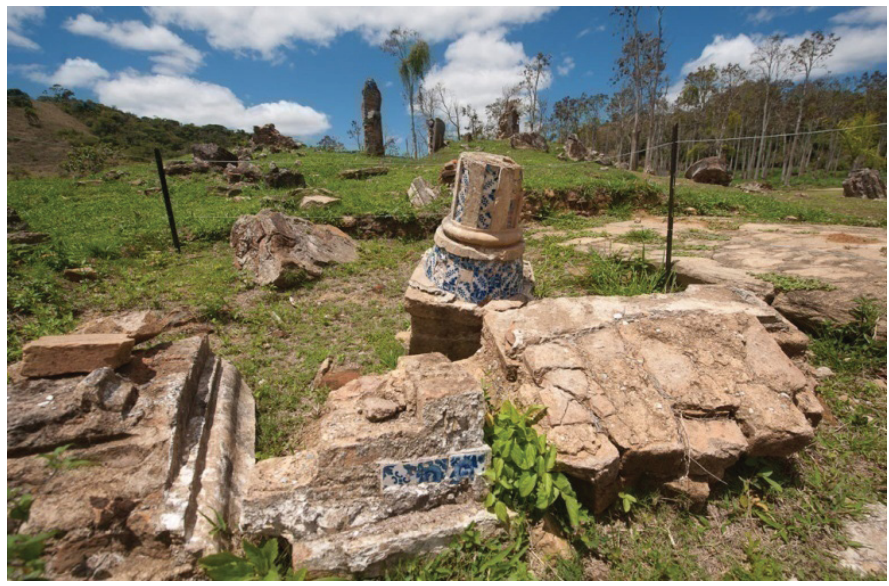

Foto: Arquivos de Sofia Moutinho

Pelo exposto na figura, percebe-se que a memória desta cidade, resta ainda, em destroços. Ou seja, a cidade é inexistente na sua materialidade completa, mas permanece na memória da população que ali viveu. O fato é que a história da cidade não servia aos propósitos da economia vigente da região.

Notou-se uma apropriação do discurso de assistencialismo social por parte do Estado, que promoveu um certo tipo de abertura para que alguns representantes da sociedade civil fossem ouvidos, nesse caso a empresa de energia, quando este bem teve o efeito do seu tombamento patrimônio histórico revogado.

O terceiro caso de cancelamento e demolição é o da Igreja de São Pedro dos Clérigos (Figura 5), localizada no Rio de Janeiro. A sua construção remonta a meados do século XVIII, por volta de 1733 a 1744, aproximadamente. O prédio foi tombado em 1938 a nível federal ( SPHAN) e seu cancelamento foi efetuado em 1943 para a abertura da Avenida Presidente Vargas. A demolição do bem aconteceu em 1944 (PAIVA, 2001). 


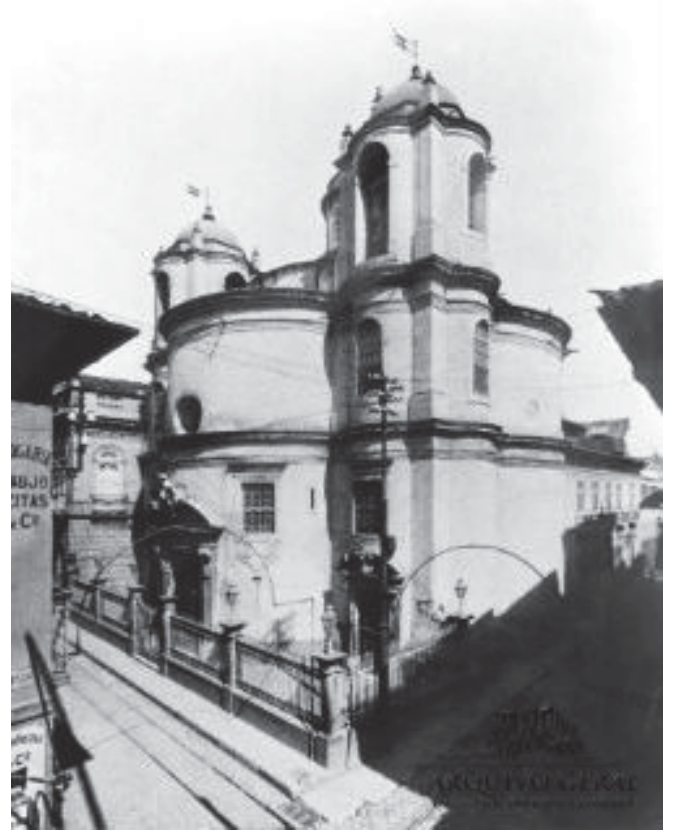

Foto: Marc Ferrez/Acervo Arquivo Geral da Cidade do Rio de Janeiro

A demolição da igreja, desse modo, fez parte do projeto de "modernização" do governo de Vargas que buscou ampliar avenidas e ruas, cancelando diversos bens tombados sem discussão com a sociedade civil. As ações de Vargas buscavam concretizar o projeto de modernização, bem como exaltar o seu "trabalho" nomeando Avenidas com o seu nome. O fato é que a história dessa Igreja não atendia aos "interesses do projeto" de Vargas, silenciando, desse modo, a memória de pedra e cal da antiga Igreja.

Enfim, gostaria de finalizar essa seção apropriando-me mais uma vez da discussão de Ortner (2007), que durante este texto mencionouse que tanto a dominação como a resistência servem a projetos, seja “[...] da autorização ou do empoderamento para perseguir objetivos e fins culturalmente significativos, sejam estes para o bem ou para o mal. E, assim, os jogos continuam" (ORTNER, 2007, p. 76). 


\section{Considerações Finais}

Evidencia-se, portanto, que, no período do Estado Novo, os interesses econômicos de alguns grupos, em especial, os ligados ao presidente da época, foram privilegiados frente aos lugares de memória. A partir de um simples ato administrativo, a abertura para o apagamento da história, via destruição dos monumentos, caracterizou-se como uma constante nesse período (1937-1945).

Busquei com este texto articular discussões de Marshall Sahlins, pois tanto esse trabalho como a minha pesquisa de doutorado buscam uma articulação entre história e antropologia. Esse teórico foi o primeiro a reivindicar uma Antropologia histórica. Em suas análises buscava ressaltar a importância da contribuição de uma discussão antropológica para a história, bem como o inverso, ou seja, procurava destacar que uma aproximação e interação dessas disciplinas, Antropologia e História, tem a contribuir com o aprimoramento de suas discussões. Nesse sentido, a discussão desse autor de história e evento foi imprescindível para o desenvolvimento desse trabalho.

Sherry Ortner (2007) foi uma autora essencial para o êxito desse trabalho mostrando que o exercício do poder dificilmente é um fim em si mesmo, ao contrário, costuma estar ao ofício de um certo projeto.

Enfim, no Brasil, a seleção da preservação de bens patrimoniais precisa ser discutida democraticamente, não podemos deixar que apenas uma minoria decida pela coletividade.

\section{Agradecimentos}

Agradeço aos professores da pós-graduação em antropologia da Universidade Federal de Pernambuco pelas contribuições sobre a temática deste artigo que foram fundamentais para o êxito do texto.

\section{Notas}

1 Projeto de extensão na área do patrimônio intitulado "Valorizando a arte, a memória e o patrimônio cultural em Roraima: ações de educação e valorização patrimonial", do qual fui coordenadora entre os anos 2014-2015, vinculado ao curso de Artes Visuais da Universidade Federal de Roraima e à Pró-Reitoria de Assuntos Estudantis e Extensão (PRAE). 
2 Projeto de pesquisa executado entre os anos de 2015-2016, sob a minha coordenação, intitulado "Os lugares de memória versus interesse político: uma análise sobre o descaso com o patrimônio cultural em Roraima".

3 O nome da autarquia de proteção ao patrimônio foi alterado por diversas vezes, mas o Serviço do Patrimônio Histórico e Artístico Nacional (SPHAN) passou a existir entre 1937 e 1946. Para maiores esclarecimentos sobre essas mudanças cf. SILVA, Cíntia Mayumi de Carli. Rio de Janeiro: CPDOC, 2010 (Dissertação). Atualmente, essa autarquia chama-se Instituto do Patrimônio Histórico e Artístico Nacional (IPHAN).

4 As sociedades, historicamente, tendem a instituir instrumentos legais de proteção ao patrimônio quando estes estão sendo ameaçados por conflitos bélicos ou quando governos ditatoriais necessitam desses instrumentos para a formação de uma identidade nacional sob os moldes do que acredita ser significativo. Nesse caso, cito o exemplo da França, que em plena Revolução Francesa criou uma comissão encarregada da preservação dos monumentos nacionais (FUNARI; PELEGRINE, 2006).

5 Por "dominação" compreendo, então, aqui, uma situação de fato, em que uma vontade manifesta ("mandado") do "dominador" ou dos "dominadores" quer influenciar as ações de outras pessoas (do "dominado" ou dos "dominados"), e de fato as influências de tal modo que estas ações, num grau socialmente relevante, se realizam como se os dominados tivessem feito do próprio conteúdo do mandado a máxima de suas ações ("obediência") (WEBER, 1999, p. 191, grifo nosso).

\section{Referências}

BOURDIEU, P. A Produção da crença: contribuição para uma economia dos bens simbólicos. 3. ed. Porto Alegre: Zouk, 2006.

BRASIL. Decreto-Lei n. 25, de 30 de novembro de 1937. Disponível em: www.planalto.gov.br. Acesso em: 10 dez. 2014.

BRASIL. Decreto-Lei n. 3.866, de 29 de novembro de 1941. Disponível em: www.planalto.gov.br. Acesso em: 10 dez. 2014.

FONSECA, Maria Cecília Londres. A invenção do patrimônio e a memória nacional. In: BOMENY, Helena (org.). Constelação Capanema: intelectuais e políticas. Rio de Janeiro: Editora FGV, 2001. p. 85-101.

FUNARI, P. P.; PELEGRINI, S. C. A. (org.). Patrimônio histórico e cultural. 2. ed. Rio de Janeiro: Jorge Zahar Ed., 2009.

GONÇALVES, Cristiane Souza. Restauração arquitetônica: a experiência do SPHAN em São Paulo 1936-1975. São Paulo: Annablume, 2007.

HALL, Stuart. As culturas nacionais como comunidades imaginadas. In: HALL, Stuart. A identidade cultural na pós-modernidade. São Paulo: DP\&A Editora, 2003. p. 47-63. 
MOUTINHO, Sofia. Uma cidade ressurge do pó. Publicado em 07/03/2012 no site do Núcleo de Pesquisa Arqueológica (NuPArq). Disponível em: http://www.ufrgs.br/nuparq/news/uma-cidade-ressurge-dopo-1. Acesso em: 10 maio 2018.

NORA, Pierre. Entre Memória e História: a problemática dos lugares. Projeto História, PUC, São Paulo, n. 10, 1993.

ORTNER, Sherry B. Poder e projetos: reflexões sobre a agência. In: GROSSI, Miriam Pillar; ECKERT, Cornelia; FRY, Peter Henry (org.). Conferências e diálogos: saberes e práticas antropológicas. Goiânia: 25 Reunião Brasileira de Antropologia; Blumenau: Nova Letra, 2007. p. 45-80.

ORTNER, Sherry B. Making gender: the politics and erotics of culture. NY: Beacon Press, 1997.

PAIVA, Celso Lago. Bens tombados destruídos no Brasil. 2001.

Disponível em: http://www.oocities.org/lagopaiva/destruid.htm. Acesso em: 10 jan. 2014.

PELEGRINI, Sandra C. A. Historicidades locais: interfaces entre as políticas públicas de preservação do patrimônio imaterial e da cultura material. In: PRIORI, Angelo (org.). História, memória e patrimônio. Maringá: Eduem, 2009. p. 77-87.

PINHEIRO, Maria Lucia Bressan. Origens da Noção de Preservação do Patrimônio Cultural no Brasil. Revista de Pesquisa em Arquitetura e Urbanismo, EESC-USP, São Paulo, 2006.

RADUN, Denis Fernando; COELHO, Ilanil. Políticas e gestão do patrimônio: Uma análise do instituto do destombamento e seus novos atores. In: II CONGRESSO INTERNACIONAL DE HISTÓRIA UEPG - UNICENTRO, 2015. Anais [...], 2015.

RODRIGUES, Ivan Dorneles. Igreja Nossa Senhora do Rosário. Setembro de 2013. Disponível em: http://web.archive.org/ web/20030429172004/http://www.rlandell.hpg.ig.com.br/igros.htm. Acesso em: 26 nov. 2019.

SAHLINS, Marshall D. Ilhas de história. Rio de Janeiro: Zahar, 1990 [1985].

TANCCINI, Thaís. Igreja de Nossa Senhora do Rosário de Porto

Alegre: entre a destruição e a preservação patrimonial. 2008. 50p. Monografia (TCC) - Universidade Federal do Rio Grande do Sul, Porto Alegre, 2008.

TOMAZ, Paulo Cesar. A preservação do patrimônio cultural e sua trajetória no Brasil. Revista de História e Estudos Culturais, [S.l.], v. 7, Ano VII, n. 2. maio/junho/agosto de 2010. ISSN 1807-6971. 
WEBER, Max. Economia e sociedade: fundamentos da sociologia compreensiva. Brasília: Editora Universidade de Brasília, 1999. v. 2.

WOLF, E. R. Antropologia e poder: organização e seleção de Bela Feldman Bianco e Gustavo Lins Ribeiro. Brasília: UNB; São Paulo: Imprensa Oficial; Campinas: Unicamp, 2003.

Recebido em 08/11/2018

Aceito em 28/10/2019

\section{Cristiane Bade}

Universidade Federal de Pernambuco, Centro de Filosofia e Ciências Humanas, Departamento de Antropologia e Museologia, Departamento, Recife, PE, Brasil. Endereço Profissional: Rua Jorge Lacerda, n. 798, Centro. Cascavel, PR. CEP: 85810-220.

E-mail: Cristiane_bade@yahoo.com.br 